\title{
6 \\ Eating and Remembering Past Cultural Achievements
}

\begin{abstract}
People in poor countries are slow to develop because their cultures do not develop as fast as the cultures of developed countries .... The cultures of the poor countries do not change fast because they do not assimilate and use new ideas and new ways from other cultures that will help to improve their way of life as fast as possible.

-Text from 2009 ghanaian Social Studies textbook, Discussed by ROCK (2018)
\end{abstract}

A generation ago, Terence Ranger (1976) described attempts to make African history usable to contemporary African peoples. He focused on the largely political projects of African leaders of early independence, who showcased past achievements to instill pride in African history and identity as part of postcolonial African nation-building. Bassey Andah made a similar pitch to archaeologists in 1995, although in more recent decades what is now known as "usable pasts" archaeology has trended towards more scientific applications, like potential uses of ancient agricultural technologies to improve production in the present day (see Logan et al. 2019). Yet whatever their lofty ambitions, rosy valorizations of the past can be at odds with the people they are supposed to help, which forms the subject of this concluding chapter. ${ }^{1}$

Younger generations often take issue with initiatives designed to promote the past for use in the present. As Ranger $(1976,22)$ put it, "the young radicals object that the poor and hungry cannot eat past cultural achievements." The "young radicals" of Ranger's day posed precisely the same question that many of my interlocutors did: "Of what use is this project to us?" Most people meant this in practical terms-how does asking about past food changes help my family eat 
today? But the younger generations also meant it in ideological terms. Tradition is a dirty word to many of the youth I have spoken with in Banda. It is associated with backwardness and plays the foil to "modern" developments in the rest of the world. To "keep with the old," as many of my young Banda interlocutors put it, is to lack vision for the future. The sentiment is not unique to Banda, as Piot demonstrates in neighboring Togo $(1999,2010)$ and Ferguson (2006) details in Lesotho. It is reinforced and (re)created by sources near and far, including in Ghana itself, as the excerpt above demonstrates.

The automatic response of many archaeologists and anthropologists to this kind of mischaracterization is to defend the past. Here caution is warranted. Not all pasts need resurrecting, and sometimes people prefer that the past stay in the past. When Ferguson $(2006,19)$, for example, extolled the virtues of traditional earthen architecture over what he saw as poor copies of the colonizer's building styles in Lesotho, he was told that those "copies" were claims to "a direction we would like to move in." Continuing to build earthen houses was not a choice, but symptomatic of a lack of options. I encountered a similar dynamic in Banda during a vernacular architecture study I pursued in 2011. It reminded me that my own interests and priorities were often very different from those of the Banda community.

With this proviso in mind, this final chapter aims to provoke questions rather than prescribe solutions. Can people eat past "achievements", and if so, how? And how should the past be remembered, and to what ends? I prod the first question by considering the interplay of the practical and ideological barriers to eating "olden times foods" in Banda. In the second and final section, I trouble the status quo with radical reimaginings of food and agriculture based on the deep history of food security covered in this book.

\section{"FOR ALL TO SEE": THE STIGMAS \\ OF HERITAGE FOODS}

Early one July morning in 2014, about thirty women assembled outside the Banda Cultural Centre. ${ }^{2}$ Within short order, they set up multiple kitchens, including three-stone hearths, pots, pans, plenty of food, and wooden mortars. Smoke soon filled the air as did the rhythmic thump-da-thump of large pestles crushing grain in the mortars. People of all ages came to observe the cooking on display. Queen Mother Akosua Kepefu and the women elders had insisted upon leaving the convenience of their own kitchens in order to show the younger generation how to make "olden times foods" in a public and socially sanctioned arena. The choice to be on display, "for all to see," as the queen mother put it, was an important one. Public visibility not only helped promote these little known dishes, but also began the process of destigmatizing olden times foods and the women who prepared them (figures 11, 12, 13, see table 2). 


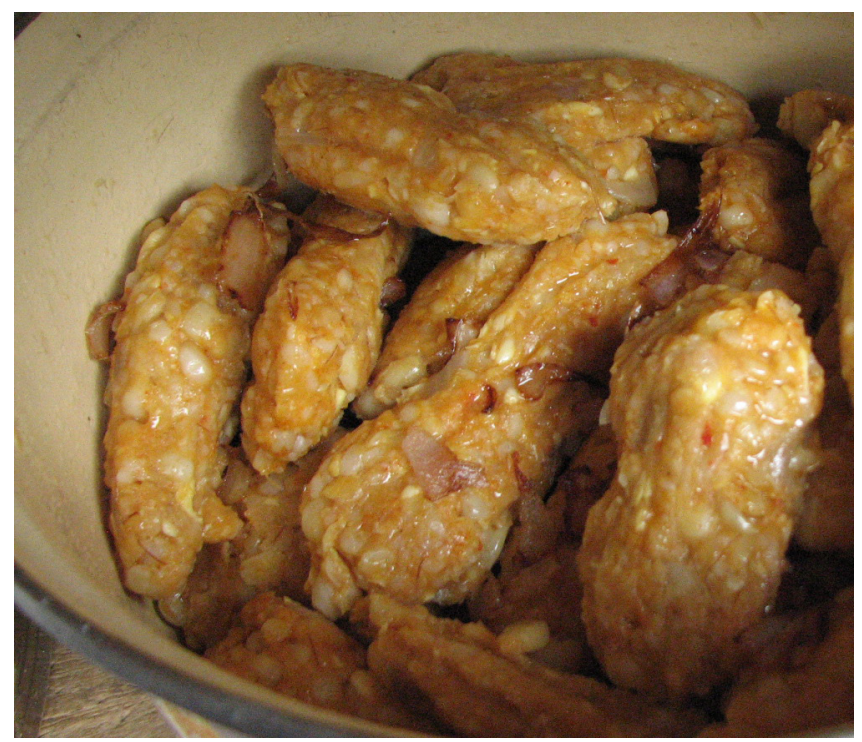

FIGURE 11. YDつrDdDkono (chapila): fresh maize dumplings steamed in maize husks (see table 2).

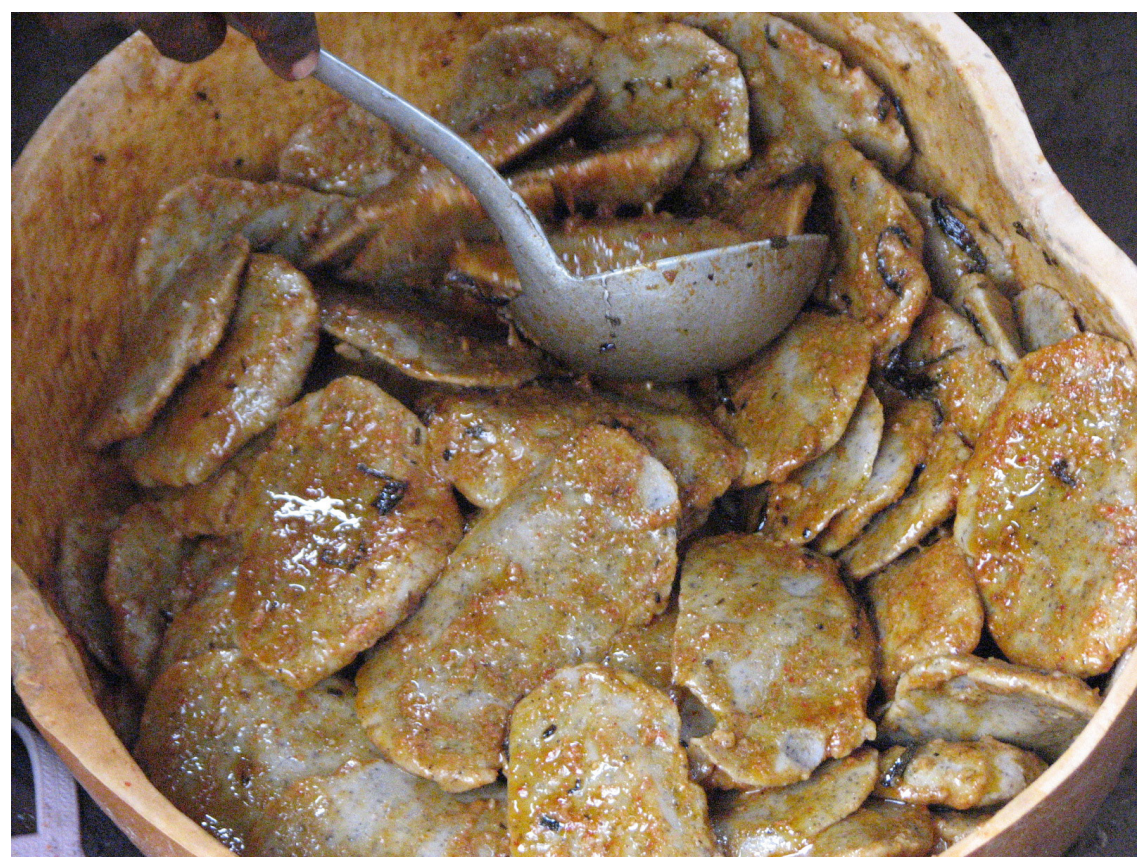

FIGURE 12. Faaro: bean dumplings steamed in leaves (see table 2). 


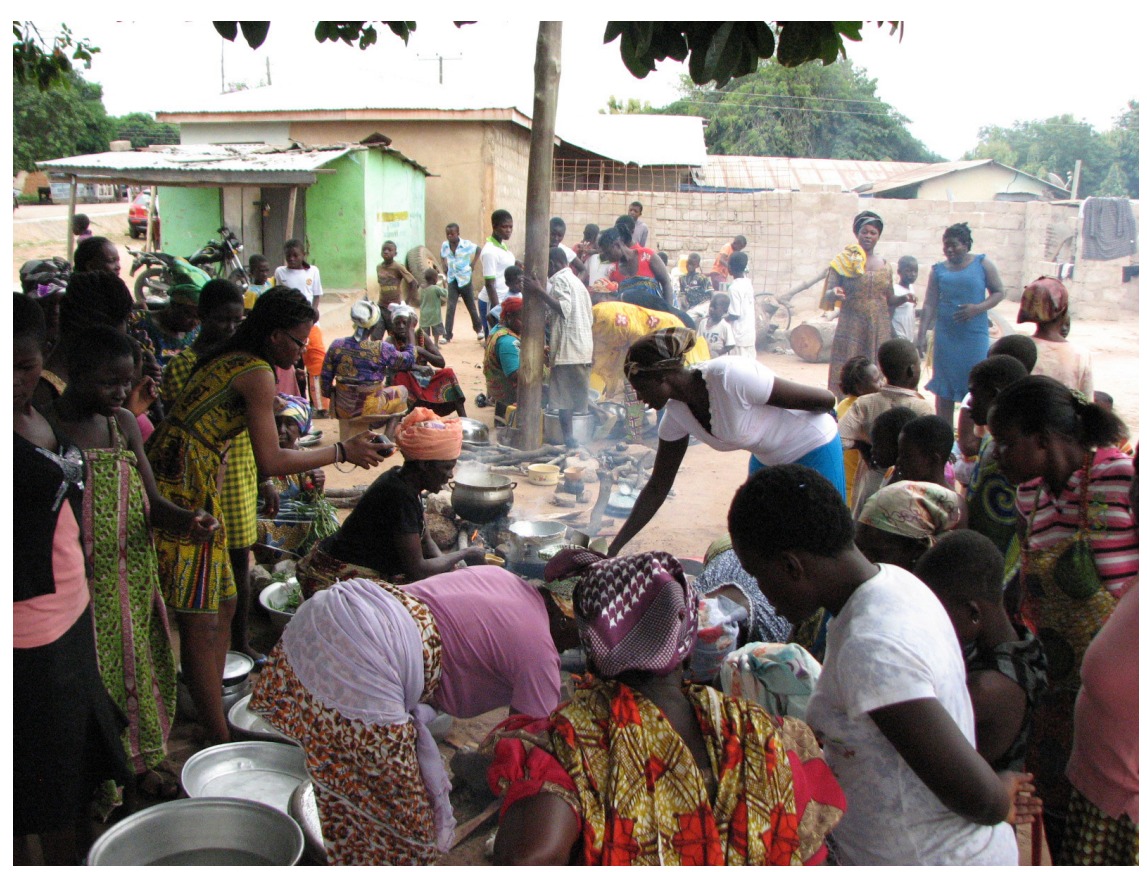

FIGURE 13. Making food for the Olden Times Food Fair.

I had encountered some of the challenges that women faced over the course of many interviews as well as in my repeated visits to the area. Most of the old women with whom I spoke in 2009 were among the poorest in their villages. Some were in ill health and passed away during my few years of absence. Yet they were repositories of knowledge and were delighted to be asked about it, since many of their experiences had not, by local standards, been considered part of the history that gets to be told.

In 2014, myself, Enoch Mensah, Zonke Guddah, and several community leaders organized a joint Heritage Day and Olden Times Food Fair. ${ }^{3}$ My goal was to provoke conversations about the use of the past in the present, particularly in the context of ever-widening generational divides. Beginning in 2007, the construction of Bui hydroelectric dam in the region had caused an almost fast-forward version of development in the area. New roads, electricity, and cell phone towers had snaked in, as did cheap wage labor at the dam site itself. During my fieldwork in 2009, frequent altercations broke out over the low pay and long hours there. The youth benefited from increased access to cash, but this only increased the gulf between them and their grandparents. The Heritage Day event, we hoped, might bridge this gap by generating conversation about what can be learned from the past. I approached the event with the hope of opening lines of communication 
between old and young, traditional and modern, rather than with a specific prescriptive goal.

As the Heritage Day event began, the early morning food preparation outside of the cultural center served to draw a crowd of curious onlookers with new smells - and the promise of free food. While the set-up crew played music on the enormous speakers common at Ghanaian events, the women elders provided a sensory sound- and smell-track of food preparation that lured the youth to the Olden Times Food Fair (figure 13).

My choice to emphasize food was deliberate. Initially I had thought foodways were a relatively uncontroversial form of heritage that would stimulate conversation and cohesion. I soon learned that food, like all forms of heritage, is contested and negotiated (Di Giovine and Brulotte 2014). Food is grown or prepared by people, and the social values assigned to individual cooks and farmers are often extended to the food itself. These social imbrications give food its value. Heritage foods often carried negative social stigmas, a value that was very much at odds with how I, as an outsider, perceived them. This divergence of views is worth exploring, because it provokes important questions about the future of food in African contexts.

In my earlier interviews, in 2009, I remember being struck by how often my female interlocutors brought up female circumcision during interviews on food. At first an odd pairing, the connection makes sense in light of my goal at the time, which was to contextualize shifts in foodways with major changes in women's lives over the last generation or two. Cessation of female nubility rites, which included circumcision as well as a constellation of other practices that marked a girl's transition into womanhood, was the most often reported significant change in women's lives. These practices formally ceased in the 1990s, because of both a national law that outlawed female circumcision and an active campaign on the part of the rapidly growing local Christian community to cease the practice. Female elders had been in charge of nubility rites, and the power and respect their positions demanded diminished when these practices ended. Not only did elderly women lose this source of authority over younger men and women, but many became increasingly stigmatized as Christianity gained traction.

The female elders themselves were a big part of why heritage foods were stigmatized. The nubility rites controversy illustrates how older women in authority positions have often been on the opposing side of Christianity, now a powerful force in Banda and throughout Ghana. This opposition came up in many conversations with my interlocutors in 2009, and seems to have grown more acute in the years since then. Many of these women feel they are no longer treated with respect, because they do not attend church and are associated with the "old ways."

During the event and even afterward, we overheard numerous conversations about whether or not the olden times foods presented were safe to eat. People were scared that the elderly women who made them-women who were themselves 
stigmatized for their spiritual choices-had poisoned or cursed the foods. At first, people went so far as to avoid some of the foods for fear that eating them would make them ill. After some discussion, most decided that since these foods were prepared out in public view in front of the cultural center, the suspect women would not have been able to curse or poison the foods. In other words, the queen mother's insistence that these foods be prepared "for all to see" was an insurance policy against later accusations of illness as well as an attempt to increase the likelihood that people would feel safe eating the food. The foods, in other words, were seen by some as imbued with the stigma of their makers.

These kinds of accusations against women in particular have long histories in Banda; archival records, for example, document accusations of poisoning against Abena of Banda in the early twentieth century (chapter 4). Women's control over the intimate domain of consumable substances is one source of their power, but also a channel through which accusations can easily flow (Douglas [1966] 2003; Lyons 2014). It was these stigmatized women who were my core interviewees and later collaborators in the Olden Times Food Fair. They valued history more than many, thus were ready-made interlocutors and collaborators. My focus on food rather than on topics that are the more traditional domain of history (e.g., the lineages of chiefs) meant that at least some of their knowledge got to matter. In the design of the associated Heritage Day event posters, I consciously attempted to combat the stigma against them by promoting women's histories in particular. But like all forms of prejudice, stigma has a certain staying power.

The stigma against olden times foods also relates to the association of some heritage foods with scarcity. During both severe and seasonal food crises, one of the most common coping mechanisms is the increased consumption of leaves from both crop plants and the bush. These are most often cooked into a kind of sauce or soup, and, as described in chapter 5 , add considerable diversity and nutritional value to otherwise starch-heavy local diets. Gora, a mixture of bean leaves and fnumu (squash seeds), is one such way of making food stretch farther. The queen mother remarked that gora was often used as a meat replacement in times when meat could not be purchased or hunted. In focus groups that followed the Heritage Day event, both old and young people remarked that foods like gora-those consumed out of necessity-would not grow in popularity. ${ }^{4}$ This is not because their taste was bad, but because they are associated with poverty. No one would purchase such foods from public street vendors because they were poor foods.

Continued preparation of foods like gora can be interpreted as motived by a desire to resurrect or uphold tradition, but we must be attuned to instances where, as Ferguson $(2006,21)$ puts it, a "traditional African way of life is simply a polite name for poverty." While poverty is not unique to elderly women, they are often among the poorest in most villages. Food-sharing norms in Banda are that a daughter-in-law provide food for her mother-in-law, a more still honored in much of the Banda area. But when times get tight, as Cliggett (2005) describes 
in Zambia, it is often the elderly women who suffer first and the most. It's no wonder they maintain their knowledge of necessity foods. The challenge is how to impart this wisdom to the younger generations who may someday need it themselves, but would not be caught dead eating or preparing poor foods (even if they are consumed out of sight). These necessity foods are associated with the recent past, back in what many youth termed the "days of ignorance."

A straightforward appeal to tradition does not impart heritage foods with value in Banda; this distinguishes African edible heritage from its counterparts in places like France or Italy. People practicing the most "traditional" lifestyles are often among the poorest. They have a much more narrow set of choices than those who are more affluent. Tradition, in this way, becomes associated with backwardness and scarcity. This situation is only compounded by external views of Africa as a place lacking in both resources and expertise. For these reasons, necessity foods may not be the way to promote African edible heritage. The youth will not eat them if they have any choice. Knowledge of such strategies can and should be maintained, but this will likely be done in secrecy, since people hide their struggles with meeting subsistence needs.

Many of our subsequent focus group discussions deliberated about what needed to happen to make olden times foods sell. Monetization of these foods is critical, and not only because the women who know how to make them are usually in dire need of cash income. The other reason is that most people encounter new and different foods when they patronize street vendors. In the context of interviews on food change that I conducted several years before the Olden Times Food Fair, I came to appreciate that while consistency and labor were valued in the home kitchen, novelty was usually experienced in the context of purchasing breakfast or lunch when out of the house for work or school. That our focus groups narrowed in on street vendors acknowledges this opportunity for the introduction of new (old) foods.

However the youth in these groups were quick to point out that olden times foods would have to be modified in certain ways for them to be desirable and sell. One simple way was to promote those foods that do not carry the stigma of poverty, as gora does. One such food is fuura (chapter 5), which was a luxury food of the chiefs in the past. It's no wonder why: fuura is incredibly time-consuming to prepare, as it's twice pounded, twice cooked, and heavily spiced. The resulting product is of a very fine, desirable texture as well. The high labor input required would, we hoped, mean that fuura would fetch a higher price, but even this would depends on how it was valued.

One other option was to promote quickly made, tasty convenience foods like sesa. Sesa is simple to prepare; it is essentially ground maize or millet mixed with a bit of sugar. This meal was widely consumed in the past by men and women on the move. Nineteenth-century accounts suggest it was the food of soldiers on long campaigns, as it did not require a fire to prepare (chapter 3 ). In the focus group, one woman remarked that she had sold sesa on occasion with great success, by 
mixing the flour with Nido milk powder and packaging the sesa in a plastic bag. Both innovations make the food more palatable because it appears and tastes more "modern." Other women suggested that some of these heritage foods be made more modern by swapping out shea butter, a cooking oil with a strong taste, for mass-produced vegetable oil, which has come to be widely used in the area. This kind of suggestion was also observed by Ham (2017) in northern Ghana as a desire for the more neutral smells and tastes of foods associated with modernity.

Some of the young men who took part in our focus group suggested that none of these foods would sell unless their look was "modernized." What they had in mind was a repackaging of sorts, so that the olden times foods would resemble industrialized food products. Why? Because then "modern people"-a group often juxtaposed against elderly women, described as "olden times people"-would buy them. This is a strategy that some women observed in other regions: repackaging of local foods made them more appealing to younger consumers. This repackaging would give these foods an aesthetic of modernity, and all of its assumed benefits, including hygiene. But I suspect there is much more at play in giving these old foods a modern look. Doing so disassociates the food from both forms of stigma I discussed. Buying packaged foods suggests people have money to do so, obscuring the roots of some of these foods in times of scarcity. Packaging also obscures the maker of the foods, suggesting an industrial-scale operation rather than an elderly woman suspected of witchcraft. Through being wrapped in plastic, olden times foods are sterilized of their association with the spiritually liminal.

The resulting aesthetic is very different from what Western consumers might expect of "local" foods. Admittedly, I have very few photographs of processed, packaged foods in Ghana precisely because they did not appeal to my aesthetic. In European and American settings, local food consumers pay top dollar for foods that come from specific farms or regions, carrying with them terroir, or taste of place (Trubek 2009). We place value on knowing who made our foods, and under what conditions. Our packaging reflects these values. But to the African consumers presented in this study, the values desired represent the other side of the coin. In nearby Togo, Charles Piot $(1999,2010)$ has documented how elements of globalization are taken up and given new meaning and context locally, not unlike how foreign objects were handled in the past. In case of Banda, modernity takes on a plastic form, enveloping stigmatized foods and rendering them edible. The aesthetic here signals edibility because it indexes how the food was made: in a modern, hygienic factory, not by your grandmother who doesn't go to church.

\section{CHALLENGING GLOBAL DEVELOPMENT DISCOURSE BY REMEMBERING THE PAST}

In essence, Banda youth were not asking if we can eat past cultural achievements, but whether we should bother at all. Some agricultural development experts, like the USAID officer presented in chapter 5, might agree. Both parties often hold 
indigenous African foodways in low esteem. And although their motivations for holding these views differ, this convergence merits discussion. The ideas of Banda youths about tradition and the past stem not only from local history and experiences of poverty, but also from a global discourse of which they are as much a part as USAID or Monsanto. The textbook example that opened the chapter illustrates what Ghanaian youth learn in school: that all innovation comes from the outside, and that African traditions must be abandoned to move forward in the world. This view is remarkably similar to views of the USAID officer described in chapter 5 . Both stem from the body of accepted wisdom about the past that I call the scarcity slot.

The negative views assigned African foodways are also closely intertwined with gender. In a recent piece in Popula, Hamza Moshood relays this dynamic in her account of "Our Day" celebrations in Ghanaian schools, in which pupils bring food to class. ${ }^{5}$ Plates are dominated by rice and biscuits-foods that must be purchased-rather than local, indigenous foods, which are looked down upon. This dynamic is as deeply gendered as it is historical. Women often cook and serve food in chop bars, ubiquitous food stalls where inexpensive local fare is offered. While men consume this food, men do not work as cooks or servers at chop bars. But it is acceptable for them to prepare and serve "white man's chop." The association of indigenous, local foods with women is clear in Banda as well, and relates to ways in which women are devalued in general.

The dense interconnectivity of the discourses of Banda youth and those of global development forces suggests that any attempt to build usable pasts must be accomplished on multiple levels. Events like the Olden Times Food Fair, or any other kind of heritage-promoting initiative, must be part of a broader push to change discourse at the global level. Past cultural achievements can be used to instill pride in local and national history, but to be effective they also need to challenge global misconceptions.

Today there is arguably a greater political need to promote the qualities and capabilities of local African foods than ever before. Multinational biotechnology corporations are making a run on Africa's genetic crop resources, and their local devaluation only facilitates this knowledge theft. Climate change projections predict a dire decrease in yields if the continent's agricultural production as practiced today does not change. This has served as a call to action for various multinational biotechnology corporations, which claim that Africa has the most to gain from GMO technology. Ethnobiologists and critical development practitioners have mounted fierce critiques of these views, illustrating the importance of preserving local landraces and ethnobotanical knowledge. Yet they face an uphill battle, especially from the better-financed corporate propaganda machines, which accuse activists of withholding live-saving crops from their constituents. Activists in turn accuse seed multinationals of neocolonialism (Rock 2019).

Biotechnology is the newest iteration of transnational development machines, whose very existence depends on the scarcity slot. A worldview in which Africans 
lack food and the ability to do anything about it themselves because they are hopelessly stuck in the past justifies and legitimatizes international development and biotechnology in particular. But what if we consider an alternate reality where such stereotypes are replaced instead with empirically grounded narratives like the one presented in this book? What would this version of reality look like, and how would it change how both Westerners and the youth of Banda think about African food and agriculture? In what follows, I present a hypothetical imaginary to prompt critical reflection on how stereotypes loom over approaches to the continent's needs. This kind of imagining reinforces precisely why history matters for resetting future possibilities.

- What if the "Africa" we heard about on the news was one that had pioneered sustainable, organic agriculture?

- What if Africans were looked to as sources of inspiration for dealing with twenty-first century climate change, given peoples' long histories of experimentation and successful adaptation to climatic variability?

- What if regional African foodways were revered in the same manner as French cuisine, and African terroir and expert chefs were lauded for their creativity and evolved methods?

- What if the superior nutritional content of West African diets was held up as the gold standard to which we all should aspire?

The thing is, none of these "what ifs" are fantastical. Each of them is grounded in empirical research. The consistent, repeated, and wholly entrenched stereotypes about the continent that I call the scarcity slot are the only reason that none of them are commonplace views in today's world.

So what would development look like in modern Africa if the "what if" story was the one that got to be told? Africans would have to be approached as experts rather than passive recipients. European interventions would have to be blamed for upsetting an otherwise sustainable system. Fingers would be pointed at the unevenness of global trade and who gets to benefit and why. In other words, accountability for Africa's food problems would be transferred from Africans and their environments to Western interventions, just as Rodney (1972) tried to do decades ago.

In this version of reality, Banda's culinary history showcases flexibility and persistence in foodways during some of the most severe environmental, political, and economic crises the world has ever seen. This narrative of resilience not only raises the specter of possibility for home-grown solutions, but also argues that we need to search for the root of Africa's food insecurity problems in other places. From the long-term perspective adopted in this book, it is clear that local foods and local knowledge have provided Banda the means to maintain food security even during the most severe drought on record in the last millennium. This success story holds salience for the climatic challenges that Banda farmers are currently facing, as well 
as for those predicted to cause grave food security challenges in the continent in coming decades.

Banda is but one point on a map. We desperately need to build longue durée histories of food security in other regions on the African continent, to capture the range of intersections of climate, history, and politics. In this book, I have argued for an empirical, interdisciplinary approach that builds on the strengths of history, archaeology, anthropology, and environmental studies, while also being critical of the assumptions these disciplines bring to the table. Disciplinary silos may lead to the uncritical reproduction of implicit prejudices, in part because of the limitations of each of our archives. As Africanists have long showcased, comparison of different source materials often reveals the fissures and tensions between disciplinary interpretations, and has provoked new kinds of questions about the past and its relationship to the present.

The past is an effective foil to the present because it can be used to expose and elevate African possibilities and capabilities. Yet, as the Ghanaian social studies textbook quote betrays, history is viewed as largely irrelevant in modern Africa. This "forgetting" has long been one of the central projects of imperialism, and is one of the most long-lasting and powerful impacts of colonial rule (Santos 2018). Forgetting is in many ways the engine of the scarcity slot. It is time to remember those pasts. It is time to raise the limits of the possible in order to reinvent food sovereign futures. That such futures are possible is suggested by the persistence and flexibility of rural foodways as well as by the longer-term histories accessed in the archaeological record. Even difficult pasts that attest to the structural and slow violences that have created modern-day insecurity have a role to play. These pasts show us that at least in Banda, food insecurity is a condition that was made, not one that has always been. Banda's histories also challenge us to recalibrate the association of modernity with progress. And they show us that the targets of development and biotechnology-Africans and their agricultural practices-are not the problem. 